University of Nebraska - Lincoln

DigitalCommons@University of Nebraska - Lincoln

Faculty Publications from the Harold W. Manter Laboratory of Parasitology

8-1988

\title{
A Plea for Improved Presentation of Type Material for Coccidia
}

Susan M. Bandioni

University of New Mexico

Donald W. Duszynski

University of New Mexico, eimeria@unm.edu

Follow this and additional works at: https://digitalcommons.unl.edu/parasitologyfacpubs

Part of the Parasitology Commons

Bandioni, Susan M. and Duszynski, Donald W., "A Plea for Improved Presentation of Type Material for Coccidia" (1988). Faculty Publications from the Harold W. Manter Laboratory of Parasitology. 160. https://digitalcommons.unl.edu/parasitologyfacpubs/160

This Article is brought to you for free and open access by the Parasitology, Harold W. Manter Laboratory of at DigitalCommons@University of Nebraska - Lincoln. It has been accepted for inclusion in Faculty Publications from the Harold W. Manter Laboratory of Parasitology by an authorized administrator of DigitalCommons@University of Nebraska - Lincoln. 


\title{
A PLEA FOR IMPROVED PRESENTATION OF TYPE MATERIAL FOR COCCIDIA
}

\author{
Susan M. Bandoni and Donald W. Duszynski \\ Department of Biology, The University of New Mexico, Albuquerque, New Mexico 87131
}

\begin{abstract}
The "true" coccidia (phylum Apicomplexa, suborder Eimeriina) constitute a large and heterogeneous group of parasitic protozoa. Despite the large number of described species (ca. 1,650) and the medical and veterinary importance of some (e.g., Toxoplasma), 2 facts are clear: (1) the majority of coccidia species are probably yet undescribed, and (2) the phylogenetic relationships of those described species are poorly known. Contributing to the latter dilemma is the lack of a tradition to provide type specimens by those who describe new species, even though the International Code of Zoological Nomenclature specifically recommends the designation of a type specimen with the description of a new species. With the publication of a new edition of the Code (1985), explicit provisions are made for the unique concerns of taxonomists working with Protozoa. Here we remind those interested in the taxonomy of coccidia of an already established method for preserving oocysts in resin and, as an alternative, suggest the standardization of a photographic procedure through which type specimens of coccidian oocysts might also be submitted to and maintained in accredited museums. Thus, coccidia taxonomists should no longer have an excuse for their failure to designate types.
\end{abstract}

The protozoan phylum Apicomplexa Levine, 1970 , comprises a large and heterogeneous group of obligate intracellular parasites including many species of medical and veterinary significance (e.g., Plasmodium, Babesia, Cryptosporidium, Eimeria, and Toxoplasma). About one-third of the approximately 4,600 described species in the phylum are placed in a single family, Eimeriidae, and the vast majority of these species are known from a single life-cycle stage, the sporulated oocyst. It is the process by which new eimeriids are described that we wish to address in this essay.

\section{HISTORICAL PERSPECTIVE}

Although the names of apicomplexans reflect the use of the International Code of Zoological Nomenclature, the taxonomic procedure followed in documenting the existence of new eimeriid species has not been consistent with the intention of the Code. For example, the Code explicitly recommends the designation of type specimens for new species, but a type tradition is lacking among taxonomists working with the Eimeriidae.

Historically, under the Zoological Code, "the type is a specimen," with the implication that the type specimen will be available for future study. Unfortunately, most scientists describing new coccidian species have not devoted attention

Received 2 October 1987; revised 18 March 1988; accepted 22 March 1988. to developing methods to preserve coccidian oocysts permanently or to other viable alternatives. Consequently, reference collections of preserved specimens of eimeriid species do not exist, with but few exceptions (e.g., Calyptospora empristica, see Fournie et al., 1985).

According to the most recent edition of the Zoological Code (Ride et al., 1985), a type specimen serves as "the objective standard of reference by which the application of the name it bears is determined, no matter how the boundaries of the taxon may change" (Article 61 (a), p. 115). Thus, the type specimen is intended to be unchanging and objective, whereas the limits of a nominal species are recognized to be subjective and transient. The type specimen, therefore, serves as an anchor for the name, and to some extent, it is the name (see Mayr et al., 1953).

The Bacteriological Code of Nomenclature (Lapage et al., 1975) allows, and indeed encourages, the submission of cultures to a type culture collection. Apicomplexans cannot be cultured axenically, and although some eimeriid species have been cultured in host cells, the technical difficulties in culturing new species isolated from wild animals preclude the routine submission of type cultures.

Both the Botanical Code (Voss et al., 1983; Article 9.3) and the Bacteriological Code (Rule $18 \mathrm{~A}$ ) have made provisions for organisms that cannot be permanently preserved: drawings are acceptable as type specimens. Previous editions of the Zoological Code have allowed illustrations 
to serve as lectotypes, but have not addressed the issue of whether illustrations may serve as holotypes. In the most recent version of the Zoological Code (1985, Article 73 (a) (iv), p. 149) the following statement is made, "Designation of an illustration of a single specimen as a holotype is to be treated as designation of the specimen illustrated; the fact that the specimen cannot be traced does not of itself invalidate the designation (emphasis ours)." We interpret this to mean that illustrations are finally acceptable substitutes for type specimens. According to Article 72 (c) (v), p. 145, “. . . in the case of a nominal species group taxon based on an illustration or description ..., the specimen illustrated or described and not the illustration or description" (is eligible as a name-bearing type). Regardless of whether the specimen or the illustration is considered the type, it seems clear that the intent of the new edition of the Zoological Code is to provide mechanisms by which type specimens can be identified for more nontraditional animal groups (e.g., protozoa). Whether we call them holotypes, syntypes, or even phototypes (=iconotype, see Frizzell, 1933) is of little concern to us. The major point of this essay is that we use the technology available to begin a type specimen tradition for the coccidia.

Given our conclusion that illustrations may be considered legitimate replacements for type specimens under the Code, an additional problem arises for biologists working on the coccidia. For an illustration to serve as a type, there is an implicit requirement that the illustration be based on a single individual. Types serve as the "last court of appeal" in disputes over the application of scientific names (Mayr et al., 1953). It is imperative that an illustration intended to serve as a type specimen represent a single individual because of the danger of basing a composite illustration on 2 or more species, a situation that would become a nomenclatural nightmare. Yet, composite drawings of sporulated oocysts are the standard form of presentation of taxonomic findings in descriptions of new eimeriid species. This is not meant to imply that composite illustrations have no value in coccidian taxonomy; rather, this very useful means of presenting taxonomic information should be supplemented by material less subject to errors of interpretation.

The Zoological Code does not explicitly address the question of the validity of names established without the designation of type specimens. Some authors (see Blackwelder, 1967, pp.
165-166) would consider such names invalid. Under such a strict interpretation of the Code, the status of most of the species names in the Eimeriidae would be uncertain. Indeed, the same taxonomic practices are undoubtedly widespread among taxonomists working on other apicomplexans; we are restricting our comments to a single family with which we are most familiar. Our objective in writing this essay, however, is not to threaten to declare hundreds of species names invalid, but to draw attention to the lack of a standard for the description of new eimeriids and to emphasize how this has impeded efforts to understand the systematic relationships among the genera and species within the Eimeriidae. Systematics, or "beta taxonomy" can only exist with a firm foundation of "alpha taxonomy" (and nomenclature) to support it. If there is no means of comparing species (i.e., no reference collections), neither phylogenetic nor phenetic relationships among species can be discerned. The literature on these organisms then can be only an endless series of descriptions and redescriptions, with valueless speculation regarding the significance of real or imagined differences.

The uses of type specimens go beyond their importance in nomenclature, however, and thus the lack of a type tradition among biologists working with the coccidia has implications beyond the invalidity of the species names. Blackwelder $(1967$, p. 166) identified 3 ways in which type specimens are useful to the scientific community. These uses of types will be considered, using specific examples drawn from the taxonomic literature on apicomplexans.

First, in poorly known groups, type specimens serve as "a source of unchallengeable characters" (Blackwelder, 1967, p. 166) for the group. The monotypic family Spirocystidae Léger and Duboscq, 1915, is sometimes cited as an example of just how little is known about some apicomplexans (Levine, 1982, 1985). The type and only species, Spirocystis nidula Léger and Duboscq, 1911, was observed only once by the original authors. Although later attempts to find other examples of this species were unsuccessful, Léger and Duboscq (1915) published their original findings. The meront stage of this organism does not resemble any known coccidian, and the oocysts, with their "vermicular sporozoites," bear a striking resemblance to nematode eggs. In short, there is little in the evidence provided that would allow this organism to be placed in the phylum Apicomplexa with any degree of confidence. If a 
type specimen existed, it would be possible to reexamine the organism and check some of the more questionable (or dubious) characters; this, in turn, would allow a reevaluation of the status of Spirocystis. In the absence of a type specimen tradition, descriptions such as this one are maintained in the literature because there is no alternative. Unfortunately, the evidence presented for the existence of Spirocystis is not much weaker than the evidence presented for the existence of many other coccidian species.

Second, in studies of intraspecific variation (and even interspecific similarities), the type specimen represents "one point which unequivocably falls within the species" (Blackwelder, 1967, p. 166). Presently there are several factors related to intraspecific variation that raise problems in eimeriid identification when studying sporulated oocysts from wild animal populations. Although the variations seen between individuals within a species are not unique to coccidians as organisms (note, for example, the great differences between breeds of dogs), coccidian taxonomists need to be reminded of their existence. For example, oocysts of one eimerian may vary greatly in size, but otherwise be indistinguishable from each other (e.g., oocysts of Eimeria separata Becker and Hall, 1931, vary in size by as much as $40 \%$ over patency; Duszynski, 1971) or oocysts presumed to represent one species may be highly polymorphic within the same or closely related host species (e.g., Eimeria reichenowi Yakimoff and Matschoulsky, 1935; Parker and Duszynski, 1986). In addition, the role of evolution in the morphologic similarity of different species in the same host (e.g., chicken eimerians; Joyner, 1982) and the fact that some species can infect unrelated host species (e.g., Eimeria chinchillae De Vos and Van der Westhuizen, 1968, see De Vos, 1970; Eimeria tamiasciuri Levine and Ivens, 1965, see Vance and Duszynski, 1985, and Hill and Duszynski, 1986) must be recognized as confounding factors when describing new coccidian species from sporulated oocysts from wild animals. The existence of a type specimen tradition, especially if large reference collections of voucher specimens were available for study, would greatly aid our dealing with such complicating factors.

Finally, the third way in which type specimens can be useful to the scientific community is that types serve as a means of checking the accuracy of published descriptions (Blackwelder, 1967, p. 166). This is in some ways comparable to the replication of an experiment in another laboratory, and it serves as a supplement to the peer review process.

The importance of type specimens (and indeed of taxonomy) goes beyond their necessity in systematics. Good taxonomy is an integral aspect of the scientific method for experimental biologists. In order to draw general conclusions from an experiment it is necessary to know that the organisms under study represent a homogeneous group. All other investigations of eimeriid coccidia, whether biochemical, physiological, immunological, etc., are undermined by a shaky taxonomic foundation.

\section{PROPOSED SOLUTIONS}

What then can be done to promote progress in eimeriid taxonomy and systematics? The publication of the newest edition of the International Code of Zoological Nomenclature (Ride et al., 1985 ) should usher in a new era in protozoan systematics. Historically, the Zoological Code has been inadequate for these organisms and, as a consequence, has been applied in a rather haphazard fashion. Now, for the first time, explicit provisions are made for the unique concerns of taxonomists working with protozoa. For the new provisions in the Zoological Code to be put into practice, we must require a reevaluation of the taxonomic procedures used with groups such as the Eimeriidae. Perhaps of greatest importance, then, is the need to create an awareness among biologists working with eimeriids of the value of designating type specimens. Building a type tradition will require not only the designation of holotypes for new species, but also the designation of lectotypes or neotypes for existing names. In addition, type species need to be designated for the known genera.

Methods of permanent preservation of coccidian oocysts now exist (Marchiondo and $\mathrm{Du}$ szynski, 1978, 1988), so there is no longer any reason not to begin to designate type specimens for those species that can be handled in this manner. In addition, the new provisions of the Zoological Code regarding illustrations provide an alternative: photography offers many of the advantages of preserved specimens at a fraction of the cost of the methods employed by Marchiondo and Duszynski (1978). Thus, when describing new species one could prepare a series of photomicrographs, chosen carefully to illustrate as many features of the new species as possible, and perhaps mounted on poster board with the nec- 

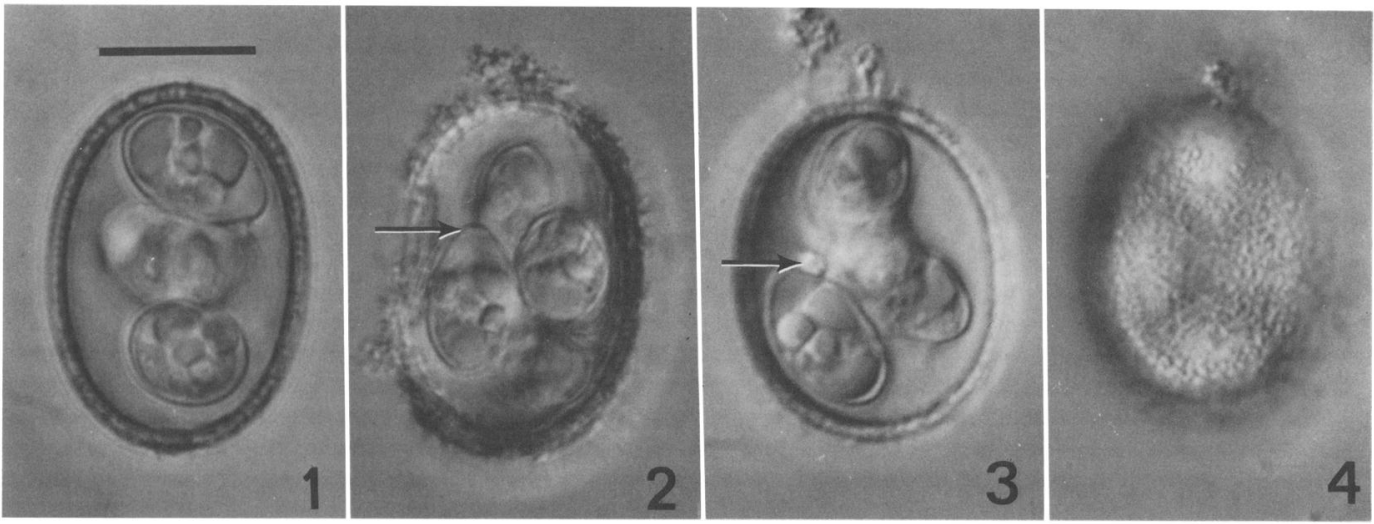

FIGURE 1. Suggested format for beginning a type specimen tradition among coccidiologists. A plate of photomicrographs of representative oocysts showing main distinguishing features of each new species.

essary structural, host, and locality data on the back (Figs. 1, 2). If we standardize the size, the poster can be submitted to, and maintained in, accredited museums just as slides of helminth types are catalogued currently. Two copies of the phototypes should probably be submitted so that one set remains permanently in the repository while the other would be on loan. Ideally, hapantotypes, composite types in which all stages in the life history are represented, should be submitted as advocated by Williams (1986). For many coccidia spp. this would be next to impossible, however, and the deposition of a syn- type (=phototype) series consisting of oocysts probably represents a more realistic goal. If reputable journals made the designation of type specimens (including type species for new genera) a requirement for publication (as most already do for helminths), there would no longer be an excuse for the failure to designate types. Type specimens are not a panacea: there is some information that cannot be obtained from preserved specimens or photomicrographs. Indeed, there is much to be gained by the collection of fresh material. However, type specimens represent a point of common ground for discussion,

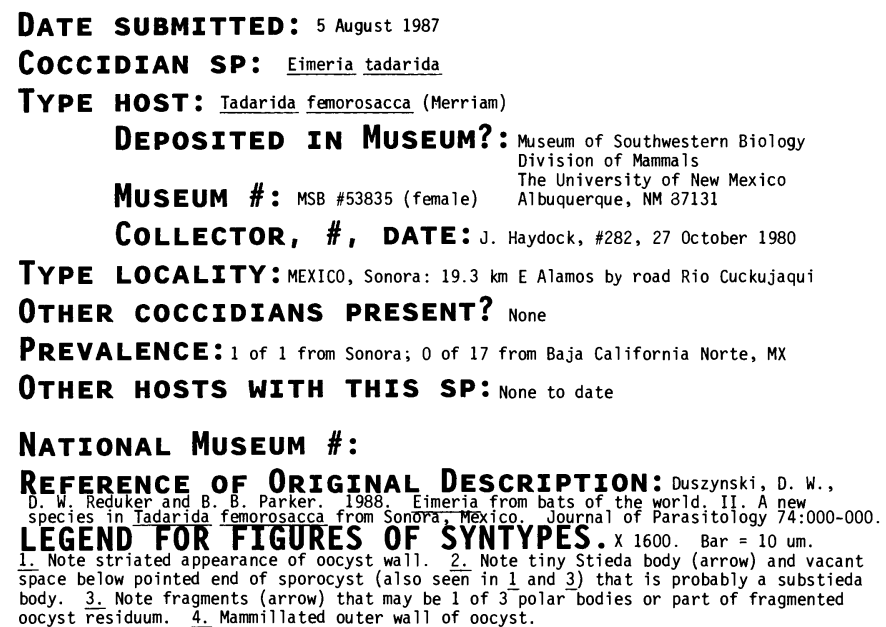

FIGURE 2. Suggested format for beginning a type specimen tradition among coccidiologists. Proposed data sheet that could be attached to the back of the posterboard with the representative oocysts. This poster, in some standardized size (e.g., $15 \times 22.5 \mathrm{~cm}$ ), could be submitted to accredited national museums for all new species descriptions. 
and only when the designation of type specimens is mandatory can the current state of eimeriid systematics change. Biologists working with the Eimeriidae would do well to heed the advice of Ferris (1928, p. 105): "The proper aim [of taxonomy] is not to name species, but to know them."

\section{ACKNOWLEDGMENTS}

Discussions with many colleagues helped shape the ideas presented here and these individuals also provided much encouragement. In particular we would like to thank Drs. T. L. Best, D. R. Brooks, J. O. Corliss, S. S. Desser, R. Fayer, J. R. Lichtenfels, S. J. Mackiewicz, A. A. Marchiondo, and M. A. Pritchard and the helpful comments of our 5 referees.

\section{LITERATURE CITED}

Blackwelder, R. E. 1967. Taxonomy: A text and reference book. John Wiley \& Sons, New York.

DE Vos, A. J. 1970. Studies on the host range of Eimeria chinchillae De Vos and Van der Westhuizen, 1968. Onderstepoort Journal of Veterinary Research 37: 29-36.

DUSZYNSKI, D. W. 1971. Increase in size of Eimeria separata oocysts during patency. Journal of Parasitology 57: 948-952.

FERRIS, G. F. 1928. The principles of systematic entomology, Vol. V, no. 3. Stanford University Publishers, Biological Sciences, pp. 101-169.

Fournie, J. W., W. E. Hawkins, AND R. M. OVERSTREET. 1985. Calyptospora empristica $\mathbf{n}$. sp. (Eimeriorina: Calyptosporidae) from the liver of the starhead topminnow, Fundulus notti. Journal of Protozoology 32: 542-547.

Frizzell, D. L. 1933. Terminology of types. The American Midland Naturalist 14: 637-668.

HILl, T. P., AND D. W. DuszYNSKI. 1986. Coccidia (Apicomplexa: Eimeriidae) from sciurid rodents (Eutamias, Sciurus, Tamiasciurus spp.) from the western United States and northern Mexico with descriptions of two new species. Journal of Protozoology 33: 282-288.

JOYNER, L. P. 1982. Host and site specificity. In The biology of the coccidia, P. L. Long (ed.). University Park Press, Baltimore, pp. 35-62.
Lapage, S. P., P. H. A. Sneath, E. F. Lessel, V. B. D. Skerman, H. P. R. Seeliger, and W. A. Clark (EDS.). 1975. International code of nomenclature of bacteria and statutes of the International Committee on Systematic Bacteriology and statutes of the Bacteriology Section of the International Association of Microbiological Societies. The American Society for Microbiology, Washington, D.C., $180 \mathrm{p}$.

LÉger, L., AND O. DuboscQ. 1915. Étude sur Spirocystes nidula Leg. et Dub. schizogregarine du Lumbriculus variegatus Mull. Archiv für Protistenkunde 35: 199-211.

Levine, N. D. 1982. Taxonomy and life cycles of the coccidia. In The biology of the coccidia, P. L. Long (ed.). University Park Press, Baltimore, pp. 1-42. 1985. Phylum II. Apicomplexa Levine, 1970. In Illustrated guide to the protozoa, J. J. Lee, S. H. Hutner, and E. C. Bovee (eds.). Society of Protozoologists, Lawrence, Kansas, pp. 322-374.

MARChIONDO, A. M., AND D. W. DUSZYNSKI. 1978. Permanent light microscopy slides of Eimeria nieschulzi oocysts. Journal of Parasitology 64: 163164.

, AND - 1988. On the status of Eimeria nieschulzi oocysts embedded in resin eleven years ago: A permanent method for preserving coccidian oocysts. Journal of Parasitology 74: 740-742.

MAYR, E., E. G. LINSLEY, AND R. L. USINGER. 1953. Methods and principles of systematic zoology. McGraw-Hill Book Company, Inc., New York.

PARKer, B. B., AND D. W. DUSZYNSKI. 1986. Polymorphism of eimerian oocysts: A dilemma posed by working with some naturally infected hosts. Journal of Parasitology 72: 602-604.

Ride, W. D. L., C. W. SABrosky, G. Bernardi, AND R. V. Melville (eds.). 1985. International code of zoological nomenclature, 3rd. ed. H. Charlesworth and Co. Ltd., Huddersfield, England, 338 p.

VANCE, T. L., AND D. W. Duszynski. 1985. Coccidian parasites (Apicomplexa: Eimeriidae) of $\mathrm{Mi}$ crotus spp. (Rodentia: Arvicolidae) from the United States, Mexico and Japan, with descriptions of five new species. Journal of Parasitology 71: 302-311.

Voss, E. G., H. M. Burdet, W. G. Chaloner, V. Demoulin, P. Hiepko, J. McNeill, R. D. Meikle, D. H. Nicholson, R. C. Rollins, P. C. Silva, AND N. GREUTER. 1983. International code of botanical nomenclature. Bohn, Scheltema \& Holkema, Utrecht/Antwerpen, Dr. W. Junk, Publishers, The Hague/Boston.

Williams, R. B. 1986. Hapantotypes: A possible solution to some problems of parasite nomenclature. Parasitology Today 2: 314-316. 